\title{
L'Université Clermont II devient l'Université Blaise Pascal
}

Jacques Fontaine

\section{OpenEdition}

Journals

Édition électronique

URL : http://journals.openedition.org/ccibp/441

DOI : $10.4000 /$ ccibp. 441

ISSN : 2493-7460

Éditeur

Centre international Blaise Pascal

Édition imprimée

Date de publication : 15 janvier 1986

Pagination : 3

ISSN : 0249-6674

\section{Référence électronique}

Jacques Fontaine, «L'Université Clermont II devient l'Université Blaise Pascal », Courrier du Centre international Blaise Pascal [En ligne], 8 | 1986, mis en ligne le 07 décembre 2015, consulté le 22 avril 2019. URL : http://journals.openedition.org/ccibp/441 ; DOI : 10.4000/ccibp.441

Ce document a été généré automatiquement le 22 avril 2019

Centre international Blaise Pascal 


\title{
L'Université Clermont II devient l'Université Blaise Pascal
}

\author{
Jacques Fontaine
}

1 Dans sa séance du 29 avril 1987, l'assemblée des trois conseils de l'Université Clermont II a ratifié la proposition du Président Jacques Fontaine, de prendre le nom d'Université Blaise Pascal. M. Le Président a bien voulu nous autoriser à reproduire le texte qu'il avait fait paraître dans le Bulletin $n^{\circ} 27$ de l'Université (21 avril 1987) pour annoncer sa proposition. Le CIBP a apporté son soutien au projet, qui inscrivait son université de tutelle, littéraire et scientifique à la fois, dans l'héritage de Pascal.

\section{Exposé du Président Jacques Fontaine sur les raisons de donner le nom de Blaise Pascal à l'Université Clermont II}

2 Le mercredi 29 avril 1987, je proposerai aux élus des trois conseils (conseil d'administration, conseil scientifique, conseil des études et de la vie universitaire), réunis en assemblée pour l'élection de mon successeur, de choisir un nom pour notre université.

3 De nombreuses universités nous ont déjà précédés dans cette démarche et il fallait trouver à Clermont une bonne occasion de les imiter. Nous n'avions pas réussi à le faire lors de l'adoption des nouveaux statuts, trop préoccupés par leur rédaction et les aspects juridiques que ceux-ci soulevaient. Ce n'est donc pas une coquetterie d'un Président sortant voulant marquer son passage par une empreinte indélébile, mais la correction d'un oubli qu'il fallait réparer.

4 L’Université a découvert tardivement la nécessité de la communication en direction de ses partenaires et des médias. Son rayonnement scientifique et culturel ne pourra que bénéficier de la nouvelle appellation qui lui sera donnée. Délaissant au seul usage de l'administration la terminologie actuelle d'« Université de Clermont-Ferrand II », nous 
pourrons utiliser les symboles et les notoriétés associés au nom que nous lui donnerons, pour une meilleure promotion de son image à travers le monde.

Il s'agit bien en effet de trouver le nom d'un homme illustre par sa vie et son œuvre, universellement connu et qui puisse s'associer le mieux à notre Université et à son actualité tout en la transcendant.

6 Je ne vois personnellement pas de savant dont le nom est aussi étroitement associé à notre ville et notre région que celui de Blaise Pascal dont le génie éclaire les disciplines scientifiques, technologiques et littéraires dont nous sommes porteurs. N'a-t-on pas implanté à Clermont-Ferrand au sein même de notre Université le Centre International Blaise Pascal ? Quelle meilleure assise aurait-il pu trouver?

7 Blaise Pascal est le "penseur et écrivain engagé, toujours au service d'une vérité qui, scientifique, morale, religieuse, se pose au-delà de l'actualité immédiate, qui demeure au moins comme question disputée, et qui fait de Pascal un contemporain permanent ».

8 Il est aussi le scientifique moderne, qui a la conviction passionnée que le progrès de la connaissance peut et doit contribuer à l'amélioration de la condition humaine.

9 Je ne soulignerai pas ici les principaux traits de ses œuvres. Ceux-ci nous le révèlent comme un physicien jouant le rôle décisif dans l'avènement de la méthode " positive » et expérimentale qui caractérise la science moderne. C'est aussi un mathématicien jetant des bases solides à un grand nombre de notions toujours modernes et dont la portée de certains aspects de l'œuvre ne se révèlera que plusieurs siècles après sa mort.

On est également séduit par l'ingénieur de génie qui invente à partir d'une approche théorique, la machine arithmétique à l'origine des calculateurs modernes. Dans sa démarche on retrouve toutes les phases de l'innovation telle qu'elle est pratiquée aujourd'hui : ingéniosité de la conception, production en série et diffusion de l'invention, marketing et protection de la propriété industrielle.

11 Je serai bien incapable de traduire ici en quelques phrases l'éloquence du penseur et de l'écrivain, mais je note simplement que depuis trois siècles il nourrit notre interrogation sur le monde et notre destin.

Bien des universitaires clermontois qu'ils soient scientifiques ou littéraires pourraient faire un plaidoyer en faveur de ce choix, bien plus éloquent que celui que j'ai ci-dessus à peine esquissé. L'assemblée du 29 avril m'a semblé une occasion à saisir pour donner une telle dénomination à notre université, en faisant participer un maximum de personnes au débat. La gravité du sujet m'obligeait d'en saisir toute la communauté universitaire dans ces quelques lignes avant de soumettre ma proposition au vote de l'assemblée. 